[ARTICLE]

\title{
NUMERAL INDETERMINATE PHRASES AND THEIR EXISTENTIAL QUANTIFICATION BY MO IN JAPANESE
}

\author{
TOSHIKO ODA \\ Tokyo Keizai University
}

\begin{abstract}
The quantificational suffix mo in Japanese has long been assumed to induce universal interpretation. However, there is a rare counterexample. The intuitive interpretation of na'n-satu-mo 'what- $\mathrm{CL}_{\text {volume }}-\mathrm{MO}$ ' is 'a large number of volumes,' which is existential. This study argues that in cases like this, the quantificational suffix mo is indeed an existential suffix, and that therefore the grammar has two types of quantificational suffix mo, namely universal mo and existential $m o *$
\end{abstract}

Keywords: numerals, indeterminate phrases, existential quantification, scalar presupposition

\section{Introduction}

This paper examines constructions in which the Japanese quantificational suffix mo follows an indeterminate phrase. In (1), the indeterminate phrase do'no gakusei 'which student' has an accent indicated by the apostrophe and is followed by mo, and do'no gakusei mo means 'every student.' Based on such examples, there is a long-standing generalization that when the quantificational suffix mo follows an accented indeterminate phrase, it induces universal interpretation (see, among others, Kuroda (1965), Shimoyama (2006), Yamashina and Tancredi (2005), and Yatsushiro (2009)).

* This paper is a revised and extended version of Oda (2012). I would like to thank Sigrid Beck and Irene Heim for their comments on the earlier version of this paper. I also thank the audience of the 29th Conference of the English Linguistic Society of Japan and the Semantics Group. I am especially grateful to Christopher Tancredi for his insightful suggestions. In addition, this paper profited strongly from the careful reading and thorough comments by two anonymous reviewers and editors of English Linguistics. All errors are my own. This work is supported by Tokyo Keizai University, Research Grant 12-04. 
(1) Do'no gakusei-mo odo-tta. which student-MO dance-Past

'Every student danced.'

(Shimoyama (2006))

However, some counterexamples are in contrast to this notion. The sentence in (2) contains what I call a numeral indeterminate phrase na'n 'what.' The intuitive meaning of the sentence is 'John read a large number of books.'

(2) John-ga hon-o na'n-satu-mo yon-da.

John-Nom book-Acc what- $\mathrm{CL}_{\text {volume}}-\mathrm{MO}$ read-Past

'John read a large number of books.'

The interpretation of (2) is puzzling: if we faithfully follow the usual generalization regarding mo, we would expect the phrase to have a universal reading, such as 'every number of books' or 'all the books.' However, na'n-satu-mo means 'a large number of books' or 'many books,' which are both existential interpretations. Therefore, the question that arises is how such existential interpretations are obtained for numeral indeterminate phrases.

I will pursue this question by testing three hypotheses, which are listed in their theoretically preferred order in (3) to (5) below.

(3) Hypothesis 1

$M o$ is a universal quantifier. The literal expression 'every number' is an exaggeration, and pragmatically means 'a large number.'

(4) Hypothesis 2

Mo is not a quantifier. It is a scalar particle 'even,' and brings the scalar presupposition that a number is large. $N a^{\prime} n$-satu 'what- $\mathrm{CL}_{\text {volume }}$ ' is bound by an invisible free existential quantifier.

(5) Hypothesis 3

$M o$ is itself the existential quantifier that binds na' $n$-satu 'what$\mathrm{CL}_{\text {volume.' }}$ Mo also serves as the scalar particle 'even.' Thus, mo plays two roles.

Hypothesis 1 is the preferred option, following the long-standing observation that the combination of an accented indeterminate phrase and the quantificational suffix mo induces universal interpretation. Hypothesis 2 is an acceptable option: both the scalar particle $m o$ and a free existential quantifier are commonly assumed in the literature, and no new mechanism needs to be assumed. Hypothesis 3 is the least preferred option because it runs contrary to the observation that the quantificational suffix mo induces universal quantification, and further requires the unconventional assumption 
that mo plays two seemingly unrelated roles. However, as I will argue in this paper, Hypothesis 3 is in fact the best alternative, as the other two hypotheses are contradicted by empirical evidence.

I will examine the three hypotheses by theoretically preferred order. The remainder of this paper is organized in the following manner. Section 2 observes behaviors of "what-CL-MO" (see the next section) as in na' $n$-satumo 'what- $\mathrm{CL}_{\text {volume}}-\mathrm{MO}$.' Section 3 reviews some previous studies that are useful in analyzing numeral indeterminate phrases. However, little research refers to the semantics of what-CL-MO. Therefore, the discussions on Hypotheses 1 and 2 in Section 4 will provide some crucial data, even though both hypotheses turn out to be empirically problematic. The conclusions obtained in Section 4 will lead us naturally to Hypothesis 3 in Section 5, which contains the main proposal of this paper. It will be shown that the empirical problems that are presented in Section 4 are solved under Hypothesis 3. In Section 6, it is argued that the phonologically identical two quantificational suffixes, the universal suffix $m o$ and the existential suffix $m o$, coexist in grammar by dividing their domains of quantification. Section 7 presents the conclusions and directions for further research.

\section{Observations}

Although ample research has been conducted on the syntax and semantics of indeterminate phrases in Japanese (Kuroda (1965), Shimoyama (2006), Yamashina and Tancredi (2005), Yatsushiro (2009), among others), there is very little research on data like (2). For the purpose of our discussion, I will schematize the sequence represented by examples such as na'n-satu-mo 'what- $\mathrm{CL}_{\text {volume}}-\mathrm{MO}$ ' as 'what-CL-MO,' where 'what' represents the indeterminate pronoun $n a$ ' $n$; CL a classifier; and MO the quantificational suffix mo. This section observes the following characteristic behaviors of whatCL-MO: 1) unexpected existential interpretation, 2) the exclusively numeral nature of $n a$ 'n 'what,' 3) a ban on the 'one' interpretation of $n a$ 'n 'what,' and 4) the locality between $n a$ 'n 'what' and mo.

\subsection{Unexpected Existential Interpretation of What-CL-MO}

Mo is not the only quantificational suffix that can follow what-CL. Other options include the existential quantificational suffix $k a$ and the free-choice suffix demo. However, what-CL-MO is the only pattern that produces an unexpected interpretation.

$\mathrm{Ka}$ induces an existential interpretation when it follows an accented in- 
determinate phrase, as in (6). Following Shimoyama (2006), I will use an apostrophe to indicate an accent, such as in $n a$ 'n 'what.' Similarly, mo induces a universal interpretation, as shown in (7). When mo follows an unaccented indeterminate pronoun, such as dare 'who,' the resultant phrase dare-mo 'what-MO' becomes a negative polarity item (NPI), as in (8). Meanwhile, demo induces a free-choice interpretation, as in (9).

Existential $\mathrm{ka}$ :

(6) Da're-ka-ga ki-ta.

who-KA-Nom come-Past

'Someone came.'

Universal mo

(7) Da're-mo-ga ki-ta.

who-MO-Nom come-Past

'Everyone came.'

NPI mo

(8) Dare-mo ko-naka-tta.

who-MO come-Neg-Past

'No one came.'

Free-choice demo

(9) Da(')re-demo kite-yoi.

who-DEMO come-allowed

'Anyone can come.'

When these suffixes apply to numeral indeterminate phrases, $\mathrm{ka}$ and demo induce expected interpretations, 'some number' and 'any number,' as in (10) and (13), respectively. However, an unexpected interpretation arises with $m o$, as already shown in (2), repeated as (11). The intuitive meaning of na'n-satu-mo 'what-CL $\mathrm{L}_{\text {volume }}-\mathrm{MO}$ ' is 'a large number/many,' rather than 'every.' Note that, in contrast to dare-mo, there is no unaccented NPI-version of what-CL-MO. For example, *nan-satu-mo 'what- $\mathrm{CL}_{\text {volume-MO' }}$ is ill formed, as in (12).

Existential $\mathrm{ka}$

(10) John-ga hon-o na'n-satu-ka yon-da. John-Nom book-Acc what- $\mathrm{CL}_{\text {volume}}-\mathrm{KA}$ read-Past 'John read some number of books.'

Mo

(11) John-ga hon-o na'n-satu-mo yon-da. John-Nom book-Acc what- $\mathrm{CL}_{\text {volume}}-\mathrm{MO}$ read-Past 'John read a large number of books.' 
NPI mo

(12) *John-ga hon-o nan-satu-mo yoma-naka-tta. John-Nom book-Acc what-CL $\mathrm{CL}_{\text {volume}} \mathrm{MO}$ read-Neg-Past. Intended: 'John read no books.'

Free choice demo

(13) John-ga hon-o na(')n-satu-demo yon-da. John-Nom book-Acc what- $\mathrm{CL}_{\text {volume}}-\mathrm{DEMO}$ read-Past 'John read any number of books.'

Therefore, what-CL-MO is the only pattern that produces an unexpected interpretation among these similar data. The traditional assumption that mo as a universal quantificational suffix does not account for the intuitive interpretation of what-CL-MO.

\subsection{Exclusively Numeral Status of $\mathrm{Na}$ 'n 'What'}

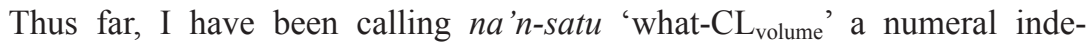
terminate phrase simply on the basis of the intuitive observation that $n a$ 'n 'what' carries a numeral reference. This needs to be further clarified, because in English, for instance, volume follows various kinds of expressions, as in two volumes, first volume, all volumes, etc. This subsection observes

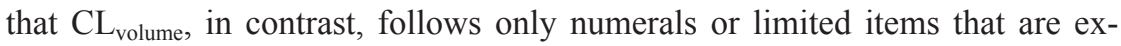
clusively related to numerals.

There are only two types of item other than $n a$ 'n 'what' that can precede a classifier. They are concrete numbers and some marked wh-expressions

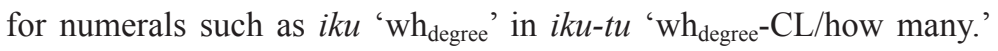
(14) John-ga hon-o san-satu-mo yon-da.
John-Nom book-Acc three- $\mathrm{CL}_{\text {volume }} \mathrm{MO}$ read-Past
'John read three books, which is a large number.'
(15) John-ga hon-o iku-tu-mo yon-da.
John-Nom book-Acc $w_{\text {degree}}-\mathrm{CL}-\mathrm{MO}$ read-Past
'John read a large number of books.'

The claim that the indeterminate phrase in what-CL-MO represents a numeral is also confirmed by the following fact. $\alpha-C L$ is ill formed when $\alpha$ is a non-numeral item.
(16) *John-ga $\quad$ tokubetu-satu/subeteno-satu\}-o yon-da.
John-Nom \{special- $\mathrm{CL}_{\text {volume}} /$ all- $\mathrm{CL}_{\text {volume }}$-Acc read-Past
'John read the special volume/all volumes\}.'

In addition, what-CL needs to have scalar meaning. For instance, $n a$ ' $n$ - $j i$ 'what time' and na'n-sai 'what age' do not induce 'large number' readings 
as we would expect. ${ }^{1}$

(17) John-ga

na’n-ji-ni kite-mo sensei-wa

John-Nom what-time-at come-MO professor-Top

kennkyuusitu-ni i-naka-tta.

office-in

be there-Neg-Past

'No matter when John came, the professor was not in his office.'

NOT: 'When John came at a late hour on that day, the professor was not in his office.'

*Nan-sai-mo-no hito-ga ki-ta.
what-age-MO-Gen person-Nom come-Past
*'A person of every age came.'
NOT: 'An elderly person came.'

(17) is understood as a universal expression, and it does not mean John came at a later hour of the day, say eleven o'clock at night. (18) is odd, and it sounds like 'A person of every age came,' which is practically impossible if it refers to one person. The sentence does not mean that an elderly person, say an 80 year old person, came. A common thread between $n a$ 'n-ji 'what time' and na'n-sai 'what age' is that they do not have scalar meaning; in other words, its being five o'clock does not entail its being four o'clock, and one's being ten years old does not entail one's being nine years old.

Finally, it is worth noting that classifiers are optional when there is an alternative element that guarantees the scalar numeral status of na'n 'what.' Some of the examples are hyaku 'hundred' and sen 'thousand.' In the example below, ken ' $\mathrm{CL}_{\text {house }}$ ' is a classifier for houses and stores. With the presence of hyaku 'hundred' or sen 'thousand,' this classifier is optional. Note that byaku in (19) and zen in (20) are contextually conditioned phonological variations.

(19) Kono kuni-ni-wa susiya-ga na'n-byak-(ken)-mo

this country-in-Top sushi_bar-Nom what-hundred-( $\left.\mathrm{CL}_{\text {house }}\right)-\mathrm{MO}$ aru.

exist

'There are hundreds of sushi bars in this country.'

${ }^{1}$ I thank Yasutada Sudo (personal communication) for bringing similar data to my attention. 
(20)
Kono kuni-ni-wa susiya-ga na'n-zen-(ken)-mo
this country-in-Top sushi_bar-Nom what-thousand- $\left(\mathrm{CL}_{\text {house }}\right)-\mathrm{MO}$ aru.
exist
'There are thousands of sushi bars in this country.'

\subsection{Ban on the 'One' Interpretation of What-CL-MO}

The numeral indeterminate phrase na'n in na'n-satu-mo 'what-CL-MO' intuitively represents some large number. Moreover, one important observation about the interpretation of what-CL-MO is that it cannot represent 'one.' For example, in (21) below, judgments among speakers vary regarding how many times can be descried as na'n-kai-mo 'what- $\mathrm{CL}_{\text {times' }}$ MO.' For instance, 'three times' may or may not be enough to say $n a$ ' $n$ kai-mo 'what- $\mathrm{CL}_{\text {times }}-\mathrm{MO}$.' However, native speakers of Japanese agree that na 'n-kai-mo 'what- $\mathrm{CL}_{\text {times }}-\mathrm{MO}$ ' cannot be 'once.' Interestingly, 'twice' is a subtle case.

$$
\begin{aligned}
& \text { John-ga na'n-kai-mo kenkyuusitu-ni ki-ta. } \\
& \text { John-Nom what-CL } \mathrm{L}_{\text {times }}-\mathrm{MO} \text { office-to come-Past } \\
& \text { 'John came to the office many times.' }
\end{aligned}
$$

Similarly in (2), the number of books that John read cannot be one. Two books is a subtle case, and speakers find it much more comfortable to understand it as three or more. The large-number expressions we have observed in Section 2.2 also come with the ban on the 'one' interpretation. For example, na'n-byaku-mo 'what-hundred-MO'/'hundreds of' is understood as at least two hundred, and preferably three hundred or more. ${ }^{2}$

The ban on 'one' is interesting, because "oneness" itself should not be a problem. In the following example, $i$ '-kko 'one-CL' has an accent and is followed by mo. The sentence is grammatical, and one (whole) apple is understood as a large amount. ${ }^{3}$

2 The ban on the 'one' interpretations on those large number expressions appears to be a little weaker than the one in other cases. An anonymous reviewer pointed out that he/ she could accept the 'one' interpretations of (19) and (20).

3 The English translation of sentence (22) is given by the author. Importantly, the sentence is ungrammatical when $i-k k o$ 'one-CL' does not have an accent.
(i) *Taro-wa ringo-o i-kko-mo tabe-ta
Taro-Top apple-Acc one-CL-MO eat-Past
'Taro ate even one apple.'

(Nakanishi (2010)) 
(22) Taro-wa ringo-o i'-kko-mo tabe-ta Taro-Top apple-Acc one-CL-MO eat-Past 'Taro ate even one (whole) apple.'

(Nakanishi (2010)) The ban on the 'one' in the interpretation of what-CL-MO will be important in Section 5.2, when we argue that $m o$ in what-CL-MO means 'even.'

2.4. Locality between Numeral Indeterminate Phrases and Mo

Another interesting behavior displayed by $m o$ in what-CL-MO is that it exhibits a locality that is different from that of the regular mo. As the following two examples show, mo normally allows long-distance relationship with an indeterminate phrase.

(23) [Da're-ga ki-te]-mo, boku-wa awu. [who-Nom come]-MO I-Top meet

'For all $\mathrm{x}, \mathrm{x}$ is a person, if $\mathrm{x}$ comes over, I meet $\mathrm{x}$.'

(Nishigauchi (1986))

(24) [Do'no gakusei-ga teisyutusita syukudai]-mo [which student-Nom submitted homework_assignment]-MO yuu-da-tta.

A-Copula-Past

'Every homework assignment that a student had submitted got an A.'

(Shimoyama (2006))

It must be noted that Shimoyama (2006) argues that the long-distance relationship is only apparent. She proposes that the universal quantifier mo takes its sister as its domain of quantification. In this sense, mo does have a local relationship with its domain. Nevertheless, for the purposes of our discussion here, I will refer to data like (23) and (24) as cases of a "longdistance" relationship between indeterminate phrases and mo, and I will review Shimoyama's analysis in Section 3.1.

Interestingly, numeral indeterminate phrases do not allow such longdistance relationship with mo. Although (25) is grammatical, it does not induce the interpretation of 'a large number,' unlike previous examples of na'n-satu-mo 'what-CL $\mathrm{L}_{\text {volume}}-\mathrm{MO}$.' The sentence instead has a universal interpretation. Therefore, na'n-satu 'what- $\mathrm{CL}_{\text {volume' }}$ and mo fail to have a "long-distance" relationship in inducing the meaning of 'a large number.'

[Na'n-satu hon-o yon-da gakusei]-mo yuu-da-tta. [which- $\mathrm{CL}_{\text {volume }}$ book-Acc read-Past student]-MO A-Copula-Past 'For all $\mathrm{n}, \mathrm{n}$ is a number, students who read n-many books got an A.'

NOT: 'Students who read a large number of books got an A.'

Let us summarize Section 2. We have observed the following character- 
istic behaviors of what-CL-MO:

(26) a. Among various types of quantificational expressions that fit into the schema of what-CL- $\alpha$, where $\alpha$ is a quantificational suffix, only what-CL-MO induces unexpected existential interpretations.

b. Na'n 'what,' when it appears in what-CL-MO, exclusively represents scalar numerals.

c. Na'n 'what' in what-CL-MO refers to more than one.

d. what-CL and mo exhibit locality when they induce an existential interpretation.

All these observations are important, but the final three play particularly important roles in specific sections: (26b) in Section 6.1, (26c) in Section 5.2, and (26d) in Section 6.2.

\section{Previous Analyses}

To the best of my knowledge, there is little prior research on what-CLMO, and Kobuchi-Philip (2010) is the only paper that discusses the semantic properties of the construction. In this section, I will first review Shimoyama's (2006) analysis of mo as a universal quantifier, as this work provides more useful analytical tools than any other research on $m o .{ }^{4}$ Then, I will review Kobuchi-Philip's (2010) analysis of what-CL-MO.

${ }^{4}$ It should be noted that there are studies that attribute the universal quantificational force of indeterminate phrases followed by mo (henceforth wh-MO) to something other than mo. Among some well-known studies in this category are Nishigauchi $(1986,1990)$ and Yamashina and Tancredi (2005). Nishigauchi assumes that the universal quantification of wh-MO comes from adverbs of quantification. Yamashina and Tancredi (2005) propose that a sum-forming operator that applies to the set denoted by an indeterminate phrase induces universal interpretations. Both studies are significant in analyzing universal interpretations of $w h$-MO. However, it is not clear if their proposals shed light on our issue of existential interpretations of what-CL-MO. Other interesting research that is worth mentioning is Ohno (1989), which points out problems with Nishigauchi's analysis. For instance, (i) is ambiguous. In addition to the reading predicted by Nishigauchi's analysis shown in (ii), it also has another interpretation (iii), where the indefinite ronbun 'paper' is existentially quantified. Such existential quantification is not predicted under Nishigauchi's analysis.

(i) Da're-ga kai-ta ronbun-mo yuu-da-tta. who-Nom write-Past paper-MO A-Copula-Past 'Papers written by no matter which person got an A.'

(ii) $\forall \mathrm{x}, \mathrm{y}[\operatorname{person}(\mathrm{x}) \wedge \operatorname{paper}(\mathrm{y}) \wedge \operatorname{wrote}(\mathrm{y})(\mathrm{x}) \rightarrow \operatorname{got}$ an_A(y)]

(iii) $\forall \mathrm{x}[\operatorname{person}(\mathrm{x}) \wedge \exists \mathrm{y}[\operatorname{paper}(\mathrm{y}) \wedge \operatorname{wrote}(\mathrm{y})(\mathrm{x}) \rightarrow$ got_an_A(y)]] 
3.1. The "Direct Restrictor View" of Shimoyama (2006)

Shimoyama adopts the Hamblin semantics of wh-phrases, under which $w h$-phrases denote a set of alternatives. In addition, she adopts what she calls the "direct restrictor view," as defined in (27).

(27) Direct restrictor view

The domain of quantification for $m o$ is provided directly by its sister constituent.

The semantics of mo under this view is given below. Mo universally quantifies over the set of alternatives denoted by its sister constituent $\alpha$, as shown in (28). In (29a), for example, the sister of mo denotes a set of students. The truth conditions are given in (29b).

(28) For $[[\alpha]]^{\mathrm{g}} \subseteq \mathrm{D}_{\mathrm{e}},[[\alpha \mathrm{mo}]]^{\mathrm{g}}=\lambda \mathrm{P} \forall \mathrm{x}\left[\mathrm{x} \in[[\alpha]]^{\mathrm{g}} \rightarrow \mathrm{P}(\mathrm{x})\right]^{5}$

(29) a. [Do'no gakusei]-mo odo-tta.

[which student]-MO dance-Past

'Every student danced.'

b. $\forall \mathrm{x}[\mathrm{x} \in\{\mathrm{y}: \operatorname{student}(\mathrm{y})\} \rightarrow \operatorname{dance}(\mathrm{x})]$

An advantage of this approach is that it enables straightforward syntax-semantics mapping, which makes it easy to capture the apparent long-distance relationship between an indeterminate phrase and mo without assuming any movement, contra Nishigauchi (1986). In (30a), the domain of quantification of mo is its sister do'no gakusei-ga teishutusita syukudai 'homework assignment submitted by which student,' which denotes a set of unique homework assignments submitted by a student. The truth conditions of the sentence are given in (30b).

a. [Do'no gakusei-ga teisyutusita syukudai]-mo

[which student-Nom submitted homework_assignment]-MO yuu-da-tta.

A-Copula-Past

'Every homework assignment that a student had submitted got an A.'

b. $\forall \mathrm{x}[\mathrm{x} \in\{\operatorname{ly}[$ homework assignment $(\mathrm{y}) \& \operatorname{submit}(\mathrm{y})(\mathrm{z})]: \operatorname{student}(\mathrm{z})\}$ $\rightarrow$ get an A(x)]

In this paper, I adopt Shimoyama's (2006) direct restrictor view and ap-

The existential reading of ronbun 'paper' in (iii) is of interest to us. However, it is not clear whether any relationship exists between this existential reading of indefinites and the existential readings related to what-CL-MO.

5 Shimoyama's original notation adopts a singleton set.

(i) For $[[\alpha]]^{\mathrm{g}} \subseteq \mathrm{D}_{\mathrm{e}},[[\alpha m o]]^{\mathrm{g}}=\left\{\lambda \mathrm{P} \forall \mathrm{x}\left[\mathrm{x} \in[[\alpha]]^{\mathrm{g}} \rightarrow \mathrm{P}(\mathrm{x})=1\right]\right\}$

(Shimoyama (2006: 155)) 
ply it to our case of what-CL-MO. As I will show in Section 6, the direct restrictor view helps us to clarify the distinction between the conventional universal $m o$ and the existential $m o$ that is proposed in this paper.

3.2. Kobuchi-Philip (2010) on the "Quasi-Quantificational Effect" of Mo

To the best of my knowledge, Kobuchi-Philip (2010) is the only available study that discusses the semantics of what-CL-MO. Her analysis shares some similarities with the proposal of this paper. Two important aspects of her proposal are described in (31) below.

(31) Kobuchi-Philip's (2010) analysis of what-CL-MO:

a. The intuitive interpretation of 'many' in what-CL-MO comes from $m o$ as a scalar particle 'even.'

b. In what-CL-MO, mo is not a universal quantifier. No lexical quantifier binds the indeterminate phrase, and as a scalar particle, mo provides "quasi-quantification."

Consider the example below. The intuitive meaning of na'n-nin-mo 'what- $\mathrm{CL}_{\text {person- }} \mathrm{MO}$ ' is 'many people,' and Philip-Kobuchi assumes that 'many' is a scalar presupposition of mo, meaning 'even.' She further assumes that there is no real quantifier to bind na'n-nin 'what- $\mathrm{CL}_{\text {person.' }}$ Thus, the semantics of (32) is basically uninterpretable, as (33) is, where na'n-nin 'what- $\mathrm{CL}_{\text {person' }}$ ' is not followed by a quantificational suffix. In order to save the uninterpretable sentence, "quasi-quantification force" is effected by the scalar particle mo. "The 'higher number than expected' presupposition of mo provides the quasi-quantificational force of 'many.' That is, whatever number is chosen, the speaker considers this more than expected, which is tantamount to "many." (Kobuchi-Philip (2010))

$\begin{array}{lll}\text { Gakusei-ga } & \text { na'n-nin-mo } & \text { hasi-tta. } \\ \text { student-Nom } & \text { what-CL } L_{\text {person-MO }} & \text { run-Past }\end{array}$

'Many students ran.'

(33) *Gakusei-ga na'n-nin hasi-tta. student-Nom what-CL $\mathrm{L}_{\text {person }}$ run-Past

Intended: 'Many students ran.'

This paper shares with Kobuchi-Philip (2010) the analysis of mo in whatCL-MO as a scalar particle. Her proposal of quasi-quantification may be controversial, but it is free from certain concerns we have with Hypothesis 3: it assumes neither two different types of quantification force on mo nor mo playing two roles. Therefore, it may be worth examining the quasiquantification further. However, I do not adopt the proposal in this paper because of a number of concerns, which are outlined below. 
First, another scalar particle sae 'even' does not have such an effect.
(34) $*$ Gra
*Gakusei-ga na'n-nin-sae hasi-tta.
student-Nom what-CL $\mathrm{L}_{\text {person- }}$-SAE run-Past
Intended: 'Many students ran.'

Second, it is not clear why mo does not carry the quasi-quantificational force in other cases. Mo follows not only numerals but also other items including individuals as shown in (35), where mo introduces a presupposition that John is the least expected person to come. (Note that mo in (35) also serves as an additive marker 'also/as well,' but that is not relevant to our discussion here.) Therefore, nothing prevents mo from focusing on an individual denoting indeterminate phrase such as da're 'who' as in (36) below. In that case, following Kobuchi-Philip's (2010) account, no quantificational operator would bind da're 'who,' but the sentence would be rescued by the quasi-quantificational force of mo. If so, we would expect the sentence to mean that whoever is chosen, the speaker is considering the person least expected. In other words, 'Some unexpected person came.' However, this prediction in not born out. (36) only means 'Everyone came.' Mo behaves only as a universal quantifier.

(35) John-mo ki-ta.

John-MO come-Past

'Even John came.'

'John came as well.'

(36) Da're-mo-ga ki-ta.

who-MO-Nom come-Past

'Everyone came.'

NOT: 'Some unexpected person came.'

It should be noted, however, that Kobuchi-Philip (2010) does not discuss the case of da're-mo 'who-MO.' If the scope of her analysis is somehow limited to what-CL-MO, this problem can be discarded.

The third problem is theoretical vagueness. It should be clarified what kind of quantificational force the quasi-quantification brings, and whether illformed semantics can truly be saved by pragmatics.

\section{Hypotheses 1 and 2}

In this section, I examine the two theoretically preferable, but empirically problematic hypotheses. This may sound circuitous, and the reader may wonder why I do not go directly to Hypothesis 3. This is because it seems necessary to demonstrate the failure of the two more obvious hypotheses in 
order to prepare the way for Hypothesis 3 .

4.1. Hypothesis 1

A non-standard assumption should be made only when problems are found in the standard assumption. On this basis, let us first test the traditional assumption that $m o$ is a universal quantificational suffix. Hypothesis 1 , which is restated as (37) below, follows from this line of reasoning.

(37) a. Mo in (2) is a universal quantifier that quantifies over the set denoted by na' $n$-satu 'what- $\mathrm{CL}_{\text {volume.' }}$

b. 'A large number' is the pragmatic meaning of 'every number' here, and this is therefore an instance of exaggeration.

Some cross-linguistic data support this analysis. Consider the German and English sentences in (38) and (39), respectively. In both cases, the literal expressions are universal, but the pragmatic meanings are existential.

(38) John kaufte jede Menge Bücher.

John bought every amount books

'John bought a lot of books.'

(39) John has every reason to complain about his job.

'John has plenty of reasons to complain about his job.'

It should be noted that these usages of jede and every are highly marked, and non-productive. Nevertheless, they are of interest to us because there is a common thread between these usages of 'every' and what-CL-MO in (2): the literal meaning of (2) can be 'John read every number of books, ${ }^{6}$ while its pragmatic meaning is 'John read a large number of books.' In fact, this kind of exaggeration is common in daily speech. Let us consider an example using minna 'everyone.'
Minna-ga
keitai-o
mot-teiru.
everyone-Nom cell phone-Acc have-TEIRU
'Everyone has a cell phone.'

The utterance may not be precise, and it is easy to imagine a situation in which there is an ignored person without a cell phone. In other words, minna 'everyone' is a universal expression in a strict sense, but it is in fact ambiguous between universal and existential meaning in a loose sense, since it can also describe existential state of affairs. The same idea applies to Hypothesis 1: what-CL-MO is a universal expression as it has been always assumed, but in cases like (2) it can describe existential state of affairs.

\footnotetext{
6 *John read every number of books is ungrammatical for native speakers of English.
} 
However, there are at least three problems with this approach. First, what-CL-MO cannot be used in a situation where it would be best understood as 'every,' as the examples below demonstrate. For example, (41) describes a situation where some books remain unread, and it is acceptable. On the other hand, (42) attempts to describe a situation where all the books are read, and it is unacceptable.

(41) (Context: According to his homework assignment, John needs to read 20 books.)

$\begin{array}{lllll}\text { John-wa moo } & \text { na'n-satu-mo } & \text { yonda-ga, mada } \\ \text { John-Top } & \text { already what- } \mathrm{CL}_{\text {volume-MO }} \text {-MO } & \text { read-but } & \text { still } \\ \text { suu-satu } & \text { nokotteiru. } & & \\ \text { several-CL } \mathrm{CL}_{\text {volume }} & \text { remain } & & \end{array}$

'John has already read many (of the books assigned), but several books still remain (to be read).'

(42) (Context: According to his homework assignment, John needs to read 20 books.)

$\begin{array}{rllll}\text { \#John-wa } & \text { na'n-satu-mo } & \text { yonda } & \text { node, moo } \\ \text { John-Top } & \text { what-CL-volumeMO } & \text { read because } & \text { already }\end{array}$

syukudai-wa owari-da.

homework_assignment-Top done-Copula

\#'Since John read many (of the books assigned), he has already completed the homework assignment.'

In contrast, similar sentences with the genuine universal quantifier minna 'all/every' yield opposite results. Given the same context, (43) is unacceptable because of the unread books, whereas (44) is acceptable.

(43) (Context: According to his homework assignment, John needs to read 20 books.)

\#John-wa moo minna yonda-ga, mada suu-satu

John-Top already all read-but still several- $\mathrm{CL}_{\text {volume }}$ nokotteiru.

remain

\#'John has already read all (of the books assigned), but several books still remain (to be read).'

(44) (Context: According to his homework assignment, John needs to read 20 books.)

John-wa minna yon-da node, moo

John-Top all read-Past because already

syukudai-wa owari-da.

homework_assignment-Top done-Copula 
'Since John read all (of the books assigned), he has already finished the homework assignment.'

The second problem arises when what-CL-MO has a scope interaction with a universal quantifier. Example (45b), which is uttered under the scenario where everyone read a different number of books, is fine; however, this could not be the case if na'n-satu-mo 'what- $\mathrm{CL}_{\mathrm{volume}}-\mathrm{MO}$ ' were semantically universal. Therefore, na'n-satu-mo 'what- $\mathrm{CL}_{\text {volume }}-\mathrm{MO}$ ' is best described as an existentially quantified expression, as shown in (45c). ${ }^{7}$

(45) a. Scenario: There are 4 people, A, B, C, and D, and there are 15 books. A read 10 books, B read 11 books, C read 12 books, and $\mathrm{D}$ read 13 books.

b. Minna-ga hon-o na'n-satu-mo yon-da. everyone-Nom book-Acc what- $\mathrm{CL}_{\text {volume}}-\mathrm{MO}$ read-Past 'Everyone read many books.'

c. $\forall \mathrm{x}[\mathrm{x}$ is a person $\rightarrow \exists \mathrm{y} \exists \mathrm{n}[\mathrm{y}$ is a book $\wedge \mathrm{n}$ is a number $\wedge \mathrm{x}$ read n-many y]]

Third, an unexpected interpretation arises when what-CL-MO is negated. For example, (46) given below is a negated version of (2).

(46) John-ga hon-o na'n-satu-mo yoma-naka-tta.

John-Nom book-Acc what-CL $\mathrm{L}_{\text {volume}}-\mathrm{MO}$ read-Neg-Past

(See (48) for intuitive interpretations.)

Predicted interpretations are given in (47). Note that because of complicated scope interactions between the three scope-taking elements-namely, the universal mo, the indefinite hon 'book,' and negation-I will focus, for the sake of simplicity, on the one that has the widest scope, passing over the scope relation of the other two. Relevant pragmatic meanings are given in parentheses.

(47) a. It is not the case that John read every number (a large number) of books. $(\neg)$

b. For every number $n$ (a large number $n$ ), John did not read nmany books. $(\forall)$

c. There are every number (a large number) of books that John did not read. $(\exists)$

Intuitively, (46) is three-way ambiguous, as shown in (48): (48a) and (48b) are predicted in (47a) and (47c), respectively. Note that (47b) is not

\footnotetext{
${ }^{7}$ I thank Yasutada Sudo (personal communication) for bringing similar data to my attention.
} 
available, most likely due to the negative island effect. ${ }^{8}$

(48) a. It is not the case that John read a large number of books.

b. There are a large number of books that John did not read.

c. John read few books.

The problematic reading is $(48 \mathrm{c})$, which arises out of nowhere. The question is, where does this reading come from?

Interestingly, similar data with a concrete number provide a clue to this problem. The use of san-satu-mo 'three- $\mathrm{CL}_{\text {volume }}-\mathrm{MO}_{\text {scalarp' }}$ in (49) also yields a three-way ambiguity as in (50), and the readings are parallel to those in (48).

(49) John-ga hon-o san-satu-mo yoma-naka-tta.

John-Nom book-Acc three- $\mathrm{CL}_{\text {volume }}-\mathrm{MO}_{\text {scalarp }}$ read-Neg-Past

(50) a. 'It is not the case that John read three books, which is a large number.'

b. 'There are three books that John did not read, which is a large number.'

c. 'John did not read three books, which is a small number.'

Importantly, in this example, mo is not a quantifier suffix but rather a scalar

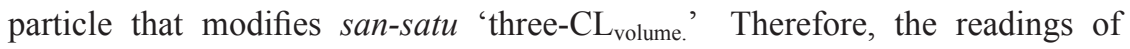
'large' and 'few' in (48) also appear to come from mo as a scalar particle, rather than from $m o$ as a universal quantifier. For the remainder of this paper, I will refer to the "few' readings in (48c) and (50c) as "small readings," following the terminology by Sudo (to appear).

The reader may suspect that the small reading in (48c) comes from $n a$ ' $n$ satu-mo 'what- $\mathrm{CL}_{\text {volume}}-\mathrm{MO}$ ' as a universal quantifier taking scope over negation because 'all not' means 'no,' which could feasibly be interpreted as 'few.' Indeed, the example in (51), 'No student is motivated,' could easily be uttered as an exaggeration, where the speaker may admit to finding one or two motivated students.

(51) Do'no-gakuse-mo yaruki-ga-nai. which-student-MO motivation-Nom-Neg

Literal meaning: 'No student is motivated.'

Possible practical meaning: 'Few students are motivated.'

However, this line of reasoning cannot be maintained for the following reasons. First, a small reading is obtained even without negation, as shown

${ }^{8}$ It has been pointed out that $w h$-words of degree cannot escape from negative islands (Ross (1984), Rullmann (1995), among others).

(i) *I wonder how tall Marcus isn't.

(Rullmann (1995)) 
in (52), where na'n-satu-mo 'what- $\mathrm{CL}_{\text {volume}}-\mathrm{MO}$ ' appears in the beforeclause.

(52) John-wa [hon-o na'n-satu-mo yomu maeni]

John-Top [book-Acc what- $\mathrm{CL}_{\text {volume }}-\mathrm{MO}$ read before] netesima-tta.

fall_asleep-Past

'John fell asleep before he had read a large number of/few books.'

Furthermore, when na'n-satu-mo 'what- $\mathrm{CL}_{\text {volume}}-\mathrm{MO}$ ' is replaced with a concrete number, san-satu-mo 'three- $\mathrm{CL}_{\text {volume }}-\mathrm{MO}_{\text {scalarp', a parallel ambiguity is }}$ (mostly) obtained. $\begin{array}{llll}\text { (53) John-wa [hon-o } & \text { san-satu-mo } & \text { yomu maeni] } \\ \text { John-Top [book-Acc } & \text { three- } \mathrm{CL}_{\text {volume }}-\mathrm{MO}_{\text {scalarP }} & \text { read } & \text { before }] \\ & \text { netesima-tta. } & & \end{array}$

fell_asleep-Past

'John fell asleep before he read three books, which is a large number/(?)few.'

Therefore, 'all not' as an exaggeration is not the source of the small reading in (48c).

In conclusion, Hypothesis 1 is empirically problematic. Given the differences between what-CL-MO and genuine universal quantifiers, it is difficult to accept that $m o$ in what-CL-MO is a universal quantificational suffix. The parallel readings of na'n-satu-mo 'what- $\mathrm{CL}_{\text {volume }}-\mathrm{MO}$ ' and sansatu-mo 'three- $\mathrm{CL}_{\text {volume }}-\mathrm{MO}_{\text {scalarP' }}$ strongly suggest that the large/small readings come from mo as a scalar particle.

\subsection{Hypothesis 2}

In this section, the possibility that mo is a scalar particle 'even' is pursued. In this case, we need to identify a binder for the numeral indeter-

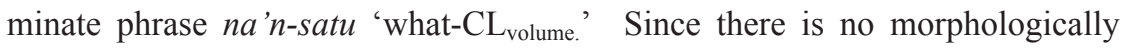
overt operator in (2), a free existential quantifier is a good candidate for the binder. Hypothesis 2 is restated in (54) below.

(54) a. Mo in (2) is a scalar particle that is similar to English even.

b. Na'n-satu 'what- $\mathrm{CL}_{\text {volume }}$ ' is bound by a free existential quantifier.

Consider the semantics of (2) under Hypothesis 2. I assume that the semantics of $m o$ as a scalar particle is the same as that of even in English, as shown in (55). When this presupposition applies to numerals, larger numbers are more unlikely than small numbers (Chierchia (2004)). For ex- 
ample, reading 5 books is more unlikely than reading 4 books, because the former entails the latter. This definition of likelihood of numerals requires the "at least" interpretation of numerals rather than "exactly n" interpretation. The meaning of (2) is a combination of an assertion and a scalar presupposition as shown in (56). ${ }^{9}$

(55) Scalar presupposition of even $p$ : $\forall \mathrm{q} \in \mathrm{C}[\mathrm{q} \neq \mathrm{p} \rightarrow \mathrm{q}>$ likely $\mathrm{p}]$

a. $\quad$ Assertion ( $\exists$ by free $\exists$-quantifier) in (2): $\exists n \cdot|\lambda x \cdot \operatorname{book}(\mathrm{x}) \wedge \operatorname{read}(\mathrm{x})(\mathrm{John})|=\mathrm{n}$

b. Scalar presupposition in (2):

$\exists \mathrm{n} \forall \mathrm{m} \neq \mathrm{n}$ : that John read n-many books is less likely than that John read m-many books, in other words, $\mathrm{n}$ is a large number.

The "at least" interpretation of numerals is crucial here, because it determines alternatives $m$. When $n$ is five, for instance, the scalar presupposition is understood as 'John's reading at least five books is less likely than the alternatives.' This implies that the alternatives are John's reading one, two, three, and four books.

However, this analysis can be challenged in at least three ways. First, (57) - which presents the same sentence as (2), but with the omission of $m o$ - is ungrammatical. This is not predicted under Hypothesis 2. When $m o$ is omitted, the scalar presupposition should disappear, but a free existential quantifier is expected to remain and induce an existential interpretation.

$\begin{array}{lll}\text { (57) *John-ga hon-o na'n-satu } & \text { yon-da. } \\ \text { John-Nom book-Acc what-CL } L_{\text {volume }} & \text { read-Past } \\ \text { Intended: 'John read some books.' } & \end{array}$

Second, the free existential quantifier is a last resort that takes effect only when there is no other operator that can bind a variable in its scope. When an overt operator such as the question marker no 'Q' is added, we would

9 The assertion and the presupposition have a potential problem: The number $\mathrm{n}$ in the assertion and that in the presupposition are not guaranteed to refer to the same n. Similar problems have been identified in the literature. The following are cited from Kadmon (2001). According to the influential presupposition projection theory by Karttunen and Peters (1979), (i) presupposes (ii):

(i) A fat man was pushing his bicycle.

(ii) A fat man had a bicycle.

The problem is that (ii) is too weak. It is not good enough to have a presupposition that some fat man had a bike. 'A fat man' in (i) and the 'fat man' in (ii) need to refer to the same fat man. However, this is not guaranteed. I will not pursue this problem further in this paper, but interested readers should consult Heim (1983) and other literature. 


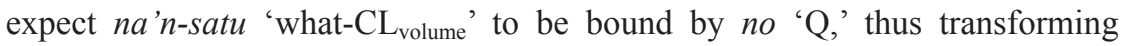
the sentence into a wh-question. However, this prediction is only partially fulfilled: (58) can be understood as a wh-question with strong accent on the wh-phrase. It is most naturally understood as an echo question, and it can be uttered in a situation where the number in question is large. ${ }^{10}$ However, the dominant reading of (58) is a yes/no question. This means that na'nsatu 'what- $\mathrm{CL}_{\text {volume' }}$ can still be bound by an existential quantifier. ${ }^{11}$

$$
\begin{aligned}
& \text { John-ga hon-o na'n-satu-mo } \quad \text { yon-da no? } \\
& \text { John-Nom book-Acc what-CL } L_{\text {volume}} \text { MO read-Past Q } \\
& \text { 'What is the number n s.t. John read even n-many books?' } \\
& \text { 'Did John read a large number of books?' }
\end{aligned}
$$

However, note that our line of reasoning seems to be on the right track. When mo is replaced by a scalar particle sae 'even,' our prediction is borne out: (59) is unambiguously a wh-question, which means that na'n-satu 'what- $\mathrm{CL}_{\text {volume' }}$ is bound by no 'Q.' Similar to the case of the interpretation of (58) as a wh-question, (59) is most naturally understood as an echo question and requires a situation where the number in question is large. ${ }^{12}$ Importantly, (59) with sae is not understood as a yes/no question. The difference between mo and sae 'even' suggests that mo is not simply a scalar particle.
?John-ga hon-o na'n-satu-sae
John-Nom book-Acc what- $\mathrm{CL}_{\text {volume }}-\mathrm{SAE}_{\text {scalarP }}$ read-Past $\mathrm{Q}$
(59)
'What is the number n s.t. John read even n-many books?'
NOT: 'Did John read a large number of books?'

The difference between mo and sae 'even' can be further confirmed by (60) and (61), given below. The sentence in (60) with san-satu-sae 'three$\mathrm{CL}_{\text {volume }}-\mathrm{SAE}_{\text {scalarP' }}$ is somewhat degraded for some native speakers but is reasonably grammatical. However, (61) with na'n-satu-sae 'what- $\mathrm{CL}_{\text {volume- }}$ $\mathrm{SAE}_{\text {scalarP' }}$ is ungrammatical, and intuitively makes no sense. This suggests that a simple scalar particle such as sae 'even' cannot follow what-CL unless there is some operator that binds what-CL.
(60) (?)John-ga hon-o san-satu-sae
John-Nom book-Acc 3-CL $\mathrm{L}_{\text {volume }}-\mathrm{SAE}_{\text {scalarP }}$ read-Past
'John read 3 books, which is a large number.'

\footnotetext{
10 Some speakers say that the interrogative sentence also has a small reading.

11 I thank Asako Uchibori (personal communication) for pointing out the ambiguity of the sentence.

12 The sentence is slightly odd, and some speakers do not accept the sentence.
} 
(61)

$$
\begin{array}{lll}
\text { *John-ga hon-o } & \text { na'n-satu-sae } & \text { yon-da. } \\
\text { John-Nom book-Acc } & \text { what-CL } L_{\text {volume}}-\mathrm{SAE}_{\text {scalarP }} & \text { read-Past } \\
\text { Intended: 'John read a large number of books.' } &
\end{array}
$$

Third, having a free existential quantifier adjoined to TP would require a reading in which the number $\mathrm{n}$ takes wide scope. However, such a reading is not available. As we have seen in (45b), which has the universal quantifier minna 'everyone' in the subject position and na' $n$-satu-mo 'what$\mathrm{CL}_{\text {volume }}-\mathrm{MO}$ ' in the object position, there is no reading of an existentially quantified number taking wide scope over minna 'everyone.'

It is worth pointing out here that the narrow scope of na'n-satu-mo 'what- $\mathrm{CL}_{\text {volume }}-\mathrm{MO}$ ' under the universal quantifier minna 'everyone' in (45b) also eliminates the possibility of $m o$ as a choice function variable, which would also entail wide scope interpretation of na' $n$-satu-mo 'what- $\mathrm{CL}_{\text {volume- }}$ MO.' (For a choice function analysis of the quantificational suffix $k a$ in Japanese, see Yatsushiro (2009).) In conclusion, an invisible existential binder is a difficult assumption to make in our analysis of what-CL-MO.

In summary, Section 4 has shown that although the two hypotheses are theoretically reasonable, both encounter empirical problems. The two important conclusions obtained from the failure of these two hypotheses are 1) what-CL-MO is better analyzed as an existential expression, and 2) mo itself is likely to be an existential quantifier. This will be our assumption in Hypothesis 3 , as described in the following section.

\section{Hypothesis 3}

This section will test Hypothesis 3, showing that it accounts for all the data presented thus far. I will provide detailed semantics of (2) and the three-way ambiguous interpretations of the negated sentence (46). In order to support the hypothesis, I also provide additional arguments for mo as a scalar particle.

\subsection{Mo Playing Two Roles}

Let us recall Hypothesis 3, as restated below in (62). The basic semantics of (2) under Hypothesis 3 are shown in (63). This is the same as in (56), with the exception that the existential quantifier is provided by mo.

(62) a. Mo itself is an $\exists$-quantifier that binds na'n-satu 'what- $\mathrm{CL}_{\text {volume.' }}$

b. Mo also serves as a scalar particle, and carries the scalar presupposition that a number is large. 
(63)
a. $\quad$ Assertion $(\exists$ by $m o$ ) in (2): $\exists$ n. $|\lambda x \cdot \operatorname{book}(\mathrm{x}) \wedge \operatorname{read}(\mathrm{x})(\mathrm{John})|=\mathrm{n}$

b. Scalar presupposition in (2):

$\exists \mathrm{n} \forall \mathrm{m} \neq \mathrm{n}$ : that John read n-many books is less likely than that John read m-many books, in other words, $\mathrm{n}$ is a large number.

Let us now return to the facts. The small readings in (46) and (52) are explained as scalar presuppositions brought by mo. The ungrammatical data in (57) and (61) are also accounted for: without mo, there is no quantifier that binds na'n-satu 'what- $\mathrm{CL}_{\text {volume.' }}$ Further, it is predicted that (58) will be ambiguous: when mo serves as a combination of an existential quantifier and a scalar particle, the sentence is understood as a yes/no question, meaning 'Did John read a large number of books?' because na'n-satu 'what$\mathrm{CL}_{\text {volume }}$ ' is locally bound by mo. When mo serves simply as a scalar particle, no 'Q' binds na'n-satu 'what- $\mathrm{CL}_{\text {volume.' }}$ Then, the sentence becomes a wh-question, meaning 'What is the number $\mathrm{n}$ s.t. John read even n-many books?' which comes with the same scalar presupposition as (63b) by mo.

The assertion of (2) can be compositionally calculated in the following manner. The LF of (2) is given in (64). The DP hon-o 'book-Acc' and na'n-satu-mo 'what-CL $\mathrm{L}_{\text {volume }}-\mathrm{MO}$ ' undergo $\mathrm{QR} .{ }^{13}$

(64) LF of (2)

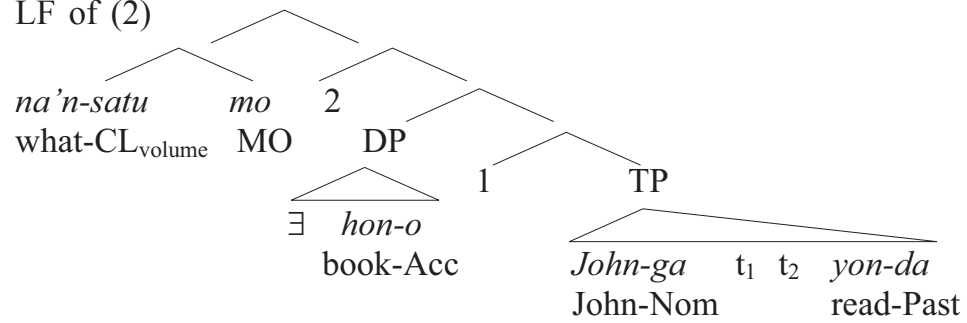

With regard to the semantic contribution of mo, I propose (65). Mo takes its argument $n a$ 'n-satu 'what- $\mathrm{CL}_{\text {volume,' and a set of cardinal numbers }}$ of type $\langle\mathrm{n}, \mathrm{t}\rangle$. The truth conditions of the assertion of (2) are given in (66), which amounts to saying that there are n-volumes of books that John read.

13 The LF syntactic structure may be a subject of revision. For the purpose of our discussion, it is convenient to assume that na'n satu mo 'what- $\mathrm{CL}_{\text {volume }}-\mathrm{MO}$ ' and the DP are independent constituents. If na'n satu mo 'what- $\mathrm{CL}_{\text {volume}}-\mathrm{MO}$ ' was part of the $\mathrm{DP}$, the $\mathrm{QR}$ of na'n-satu-mo 'what- $\mathrm{CL}_{\mathrm{volume}}-\mathrm{MO}$ ' would be the case of movement out of a moved item. (See Takahashi (1994) and others.) 
(65) For $[[\alpha]]^{\mathrm{g}} \subseteq \mathrm{D}_{\text {cardinal numerals, }}$ $\left[\left[\alpha m_{0}\right]\right]^{\mathrm{g}}=\lambda \mathrm{P}_{<\mathrm{n}, \triangleright>} \exists \mathrm{n}\left[\mathrm{n} \in[[\alpha]]^{\mathrm{g}} \wedge \mathrm{P}(\mathrm{n})\right]$ $[[(64)]]^{\mathrm{g}}=1$ iff $\exists \mathrm{n}[\mathrm{n} \in\{\mathrm{m}: \operatorname{volumes}(\mathrm{m})\} \wedge \exists \mathrm{x}[\operatorname{book}(\mathrm{x}) \wedge|\mathrm{x}|=\mathrm{n}$ $\wedge \operatorname{read}(\mathrm{x})(\mathrm{John})]]$

The scalar presupposition of 'a large number' is added pragmatically. How scalar particles carry the relevant scalar presupposition is still a matter of debate, particularly when they appear in negated sentences. Before explaining the three-way ambiguous interpretations of the negated sentence (46), I would like to briefly discuss the background of this debate.

The question goes back to the ambiguous reading associated with even in downward entailing context. In the following example from Karttunen and Peters (1979), Syntactic Structures is understood as either a difficult book or an easy book to read. Similar ambiguities arise when even appears in a downward-entailing environment.

(67) It is hard for me to believe that Bill understood [NP even SYNTACTIC STRUCTURES] (Karttunen and Peters (1979)) There are two schools of thought regarding how the "easy reading" is obtained: Karttunen and Peters, as well as Willkinson (1996), Guerzoni (2003), and others adopt the so-called scope theory, whereas Rooth (1985), von Stechow (1991), Rullmann (1997), and others adopt the so-called lexical theory. Essentially the same arguments apply to the scalar particle mo in Japanese. The "small reading" in our case corresponds to the easy reading of (67), and will be captured by either the scope theory or the lexical theory. Nakanishi (2008) argues, through observation of data with go-satu-

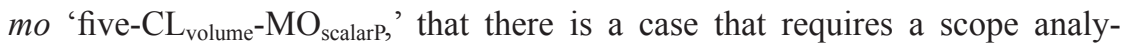
sis. Meanwhile, Sudo (to appear) argues that the distribution of small readings is better accounted for by a lexical analysis. In this paper, I will not commit to either analysis of mo, and instead will tentatively use the terms "large $m o$ " and "small mo" simply to mean " $m o$ that brings a large/small reading in a given environment."

Bearing this in mind, let us return to the three-way ambiguous data (46), which is repeated in (68) below. In (69)-(71), assertions and scalar presuppositions are provided for each interpretation. ${ }^{14}$ Importantly, the three read-

\footnotetext{
14 It is worth noting that these three readings are similar to the ones for (i) with a concrete number discussed in Nakanishi (2010: 269). Nakanishi adopts the scope analysis of $m o$ and argues that the three interpretations associated with (i) are obtained through the scope interaction of mo, 'five,' and the negation, as shown in (ii). Note that the English paraphrases are provided by the author.
} 
ings are derived according to two factors: 1) where the negation takes scope and 2) whether "large $m o$ " or "small $m o$ " is adopted.

(68) John-ga hon-o na'n-satu-mo yoma-naka-tta.

John-Nom book-Acc what-CL $\mathrm{L}_{\text {volume }}-\mathrm{MO}$ read-Neg-Past

a. It is not the case that John read a large number of books.

b. There are a large number of books that John did not read.

c. John read few books.

(69) (For (68a)) It is not the case that John read a large number of books.

a. Assertion:

$\neg \exists \mathrm{n}[\mathrm{n} \in\{\mathrm{m}: \operatorname{volumes}(\mathrm{m})\} \wedge \exists \mathrm{x}[\operatorname{book}(\mathrm{x}) \wedge|\mathrm{x}|=\mathrm{n} \wedge \operatorname{read}(\mathrm{John})$ $(\mathrm{x})]]$

b. Presupposition of "large $m o$ ":

$\exists \mathrm{n} \forall \mathrm{m} \neq \mathrm{n}$ : that John read n-many books is less likely than that John read m-many books, in other words, $\mathrm{n}$ is a large number.

(70) (For (68b)) There are a large number of books that John did not read.

a. Assertion:

$\overline{\exists n[n \in\{\mathrm{m}}: \operatorname{volumes}(\mathrm{m})\} \wedge \exists \mathrm{x}[\operatorname{book}(\mathrm{x}) \wedge|\mathrm{x}|=\mathrm{n} \wedge \neg \operatorname{read}(\mathrm{John})$ (x)]]

b. Presupposition of "large mo":

$\exists \mathrm{n} \forall \mathrm{m} \neq \mathrm{n}$ : that John read n-many books is less likely than that John read m-many books, in other words, $\mathrm{n}$ is a large number.

(i) [Go-nin $]_{\mathrm{F}}-\mathrm{mo}$ ko-naka-tta.

five-CL-MO come-Neg-Past

Lit. 'Even five people did not come.'

(ii) a. $\neg>m o>5$ 'It is not the case that even five people (that many people) came.'

b. $\quad m o>5>\neg$ 'There are even five people (that many people) who did not come.'

c. $m o>\neg>5$ 'It is not the case that even five people (only such few people) came.'

Nakanishi further points out that the reading of (iic) is problematic for the lexical analysis of mo. For details, please refer to pp. 257-270 in Nakanishi (2010). I thank an anonymous reviewer for bringing the paper to my attention. 
(71) (For (68c)) John read few books.

a. Assertion:

$\neg \exists \mathrm{n}[\mathrm{n} \in\{\mathrm{m}: \operatorname{volumes}(\mathrm{m})\} \wedge \exists \mathrm{x}[\operatorname{book}(\mathrm{x}) \wedge|\mathrm{x}|=\mathrm{n} \wedge \operatorname{read}(\mathrm{John})$ $(\mathrm{x})]]$

b. Presupposition of "small $m o$ ":

$\exists \mathrm{n} \forall \mathrm{m} \neq \mathrm{n}$ : that John read n-many books is more likely than that John read m-many books, in other words, $\mathrm{n}$ is a small number.

Finally, a comparison between what-CL-MO and a similar construction, namely what-CL-KA will help clarify the point. Let us first recall the relevant data of what-CL-KA in (10) below as (72).

(72) John-ga hon-o na'n-satu-ka yon-da.

John-Nom book-Acc what- $\mathrm{CL}_{\text {volume}}-\mathrm{KA}$ read-Past

'John read some number of books.'

Unlike (2) that comes with mo, there is no scalar presupposition involved in the meaning of (72). This is because $k a$ is simply an existential quantifier. The semantics of (72) is the same as the assertion of (2), which has been shown in (66).

5.2. Evidence for Alternative Sets and Mo as 'Even': the Semantics of 'Even One'

In the analysis of what-CL-MO in Section 5.1, both alternative sets for indeterminate phrases and $m o$ as a scalar particle are crucial. This subsection attempts to provide additional evidence for these two assumptions. I will argue that the ban on the 'one' interpretation of what-CL-MO observed in Section 2.3 is a natural consequence when indeterminate phrases as alternative sets and $m o$ as a scalar particle are combined. ${ }^{15}$

I assume that the ban on the 'one' interpretation is related to Lahiri's (1998) argument that 'even one' needs to be an NPI. Let us first review the argument. In Hindi, ek bhii 'any/one even' is an NPI, as the following contrast shows:

(73) $*[\mathrm{ek}]_{\mathrm{F}}$ bhii aadmii aayaa.

any man came

'Any man came.'

15 Note that what-CL-KA as in (72) does not have the interpretation of 'one,' either. In other words, the sentence can not be interpreted as 'John read one book.' It is not clear at this point how this ban on 'one' arises. In any case, the analysis of Section 5.2 does not apply, because the sentence does not have any scalar particle. 
(74) $[\mathrm{ek}]_{\mathrm{F}}$ bhii aadmii nahiiN aayaa. any man didn't come

'No man came.'

(Lahiri (1998))

Example (73) is ungrammatical for the following reason. Assuming that bhii 'even' yields scalar presupposition like even in English, we obtain the scalar presupposition that 'that one man came' is the least likely proposition among the alternatives. However, this is odd, because the relevant alternatives are that one man came, that two men came, that three men came, ..... , where 'that one man came' is entailed by all others and is thus the weakest (the most likely) one. Therefore, the scalar presupposition and the alternatives are inconsistent with each other. ${ }^{16}$

On the other hand, (74) is grammatical. Under the scope theory of even, which Lahiri adopts, bhii takes scope over negation, and the focus alternatives are that it is not the case that one man came, that it is not the case that two men came, that it is not the case that three men came, ..... . 'That it is not the case that one man came' is the strongest (the least likely) among the alternative, which is equivalent to say that 'that one man came' is the weakest (the most likely) one. Therefore, the scalar presupposition and the alternatives are consistent.

Let us now turn to (21), repeated as (75). The relevant set of alternatives is given in (76).

(75) John-ga na'n-kai-mo kenkyuusitu-ni ki-ta.

John-Nom what-CL $\mathrm{CL}_{\text {times }} \mathrm{MO}$ office-to come-Past

'John came to the office many times.'

(76) that John came to the office once, that John came to the office twice, that John came to the office three times, .....

'That John came to the office once' is the weakest alternative, and thus cannot be less likely than any other alternative. In other words, 'once' is not a possible interpretation for the same reason that ek bhii 'any/one even' is ungrammatical in affirmative sentences. This problem does not arise with 'twice,' because it has at least one weaker alternative, namely 'once.' However, 'twice' is not a preferred alternative, because it has only one weaker alternative, 'once.' This is why 'twice' is a subtle case and native

\footnotetext{
16 In the case of (22), where $i$ ' $k$ ko 'one-CL' comes with an accent, it remains grammatical. This is because ringo-o i'kko-mo 'apple-Acc one-MO/even one apple' is considered a large amount, and alternatives are smaller amounts, for instance, half an apple or a bit of an apple. This interpretation is possible only when $i$ 'kko 'one-CL' comes with an accent. Without the accent, ikko 'one-CL' is an NPI as ek bhii 'any/one man' in Hindi.
} 
speakers do not prefer to interpret the sentence as John's coming to the office 'twice.' Native speakers are much more comfortable interpreting it as 'three times or more,' because that interpretation has two or more than two weaker alternatives, namely 'once,' 'twice,' and so on.

Similarly, the semantics of 'even one' also explains the intuitive interpretations of (19) and (20). In (19), the intuitive translation of na'n-byaku-mo 'what-hundred-MO' corresponds to hundreds of in English, where one hundred is not an option. Since 'that there are one hundred sushi bars in this country' is the weakest (the most likely) among the alternatives as shown in (77) below, it is not compatible with the scalar presupposition of mo. Similarly, na'n-zen-mo 'what-thousand-MO' is not understood as one thousand.

(77) \{that there are one hundred sushi bars in this country, that there are two hundred sushi bars in this country, that there are three hundred sushi bars in this country, ....

This section has shown that Hypothesis 3 is the best option among the three hypotheses, thought it is theoretically less preferable than the other two. The most important part of the hypothesis is that mo serves as an existential quantifier. Hypothesis 3 is the least theoretically preferred choice, but it is an inevitable one. If what-CL-MO is not existentially quantified, it must be universally quantified, and that would contradict the data. It was also shown that the ban on the 'one' interpretation of what-CL-MO supports the additional role of $m o$ as 'even.'

\section{Universal vs. Existential Mo}

Now, we have two types of quantificational suffix mo with different quantificational forces - that is, the universal mo and the existential mo. A question immediately arises as to how the two types of mo can co-exist within the grammar of Japanese. I argue that these two types of mo are distinguished by their domain of quantification.

\subsection{Environments for the Universal and the Existential $M o$}

Using Shimoyama's direct restrictor view, the two types of mo are justified by defining a unique environment for each type of mo. These environments are determined by the semantics of the sister constituents of mo, that is, the domain of quantification. It has already been clarified in Section 2.1 that what-CL-MO is the only case in which mo induces an existential interpretation. Thus, it is a good idea to define the environment for the existential mo and to let the universal mo take the complement. 
In Section 2.2, it was seen that in what-CL-MO, na'n 'what' represents scalar numerals. Therefore, the domain of existential mo is defined as a set of scalar alternatives. The domain of universal mo is defined as its complement.

(78) Distribution of universal $m o$ and existential mo

$M o$ is an existential quantifier when its sister denotes a set of scalar alternatives. Otherwise, it is a universal quantifier.

The definitions of the two type of mo presented so far match the distribution. The domain $\alpha$ for the existential $m o$ is the set of cardinal numerals. Thus, the denotation of $\alpha$ is always a set of scalar alternatives. In contrast, $\alpha$ for the universal mo proposed by Shimoyama (2006) is a set of individuals, thus it denotes a set of non-scalar alternatives.

(79) For $[[\alpha]]^{\mathrm{g}} \subseteq \mathrm{D}_{\text {cardinal numerals, }}[[\alpha m o]]^{\mathrm{g}}=\lambda \mathrm{P}_{<\mathrm{n}, \mathrm{t}>} \exists \mathrm{n}\left[\mathrm{n} \in\left[[\alpha]^{\mathrm{g}} \wedge \mathrm{P}(\mathrm{n})\right]\right.$

(80) For $[[\alpha]]^{\mathrm{g}} \subseteq \mathrm{D}_{\mathrm{e}},[[\alpha m o]]^{\mathrm{g}}=\lambda \mathrm{P} \forall \mathrm{x}\left[\mathrm{x} \in[[\alpha]]^{\mathrm{g}} \rightarrow \mathrm{P}(\mathrm{x})\right]$

In summary, having the two types of quantificational suffix mo in the grammar is justified because each type of mo has its distinct environment.

Nevertheless, the coexistence of the two types of mo requires a more fundamental explanation. Since the existential use of $m o$ is peripheral, it would be natural to assume that something prevents mo from being the universal quantifier when its sister denotes a set of scalar alternatives. Thus the first question is what this is. Even if this question is answered, another question remains as to why what-CL-MO induces existential interpretations instead of just being ill-formed. I do not have any clear answers to these questions at this moment, but I would like to present some ideas for further research.

Regarding the question of why what-CL-MO does not have a universal interpretation, this might be because it is hard to obtain a situation where John's reading every number of books is true, or it could be the case that reading every number of books is nonsense. In fact, *John read every number of books is odd in English. The source of the oddness could also be related to potentially undefined semantics when a universal quantifier quantifies into a set of scalar alternatives. For instance, na'n-satu 'what$\mathrm{CL}_{\text {volume }}$ ' basically denotes the set of \{one volume, two volumes, ...... volumes $\}$. Since reading $\infty$ volumes of books is undefined, this could be the reason why universal quantification is not allowed over the set. However, this is a very weak argument, since domains are usually restricted by context, and such a contextually defined upper limit would prevent such undefined meaning.

As for the next question of why what-CL-MO remains grammatical and 
why it turns into an existentially quantified expression, I would simply say that nothing prevents mo from being an existential quantifier once its unique domain of quantification is provided. Detailed discussions are left for further research.

\subsection{Locality}

The distribution of the universal and the existential mo stated in (78) explains the contrast in locality between the two types that we observed in Section 2.4. Recall the relevant example: In (81), na'n-satu 'what- $\mathrm{CL}_{\text {volume' }}$ has a long-distance relationship with $m o$, and it has only a universal interpretation. This is predicted by our analysis, as the sister constituent of $m o$ in this case is not a set of scalar alternatives but a set of individuals, namely students who read some books. ${ }^{17}$

(81) [Na'n-satu hon-o yon-da gakusei]-mo yuu-da-tta. [which- $\mathrm{CL}_{\text {volume }}$ book-Acc read-Past student]-MO A-Copula-Past 'For all $\mathrm{n}, \mathrm{n}$ is a number, students who read n-many books got an A.'

NOT: 'Students who read a large number of books got an A.'

In this section I argued that the two types of mo can co-exist within the grammar. They show complementary distribution, which is derived from their domains. The locality between numeral indeterminate phrases and the existential mo that we observed in Section 2.4 is a natural consequence of the semantics of the existential mo.

\section{Conclusion}

In this paper, I have discussed the semantic properties of numeral indeterminate phrases followed by mo, which I schematize as what-CL-MO. This paper contributes to the existing literature in the following manner. Em-

17 Interestingly, amount nouns do not induce existential interpretations. The following example, with the head noun sas-suu 'volume-number' has only universal interpretation:

(i) [John-ga na'n-satu hon-o yon-da sas-suu]-mo

[John-Nom which-CL $\mathrm{C}_{\text {volume }}$ book-Acc read-Past volume-number]-MO

Bill-ni kanawa-naka-tta.

Bill-for match-Neg-Past

'Whatever the number of volumes John read was no match for (that of) Bill.'

NOT: 'A large number of volumes John read was no match for (that of) Bill.'

It might be the case that sas-suu 'volume-number' is interpreted as a definite description 'the number of volumes,' which would prevent it from denoting scalar alternatives. 
pirically, I have presented novel data related to what-CL-MO, which has somehow mostly escaped attention until now. The data provide important counterexamples to the long-standing generalization that the quantificational suffix mo has only a universal interpretation. Accordingly, I propose that there is an existential quantificational suffix mo that is morphologically identical to the universal quantificational suffix mo, but induces existential interpretation. I also propose that the existential quantificational suffix mo in what-CL-MO also serves as a scalar particle 'even.' It has been shown that these two proposals combined accounts for the empirical facts.

At the same time, the proposal which I argued for here encounters major challenges. The two most urgent are described in (82), below.

(82) a. There are already too many instances of mo assumed in the literature. Hypothesis 3 adds yet another instance of $m o$.

b. The assumption of "mo playing two roles" requires more empirical and theoretical support.

The problem of "too many $m o$ " is not new. It has long plagued researchers, and I am not able to provide any innovative solution. The second problem, "mo playing two roles," may not be a serious problem if more empirical and theoretical support is provided for this assumption. I would like to briefly introduce some English data of interest. In the following example, some is not simply an existential quantifier: rather it carries the implication that the party was very good or remarkable. ${ }^{18}$

(83) That was some party last night.

Thus, some in this case plays two similar roles to those we have claimed for mo. It is not clear how the two roles are assigned to some. To my knowledge, Israel (1999) is the only paper that mentions this particular usage of some, which she calls "exclamative some." However, there is as yet no detailed analysis of this phenomenon, and it remains for further research to determine whether such data might shed any light on the investigation of mo.

\section{REFERENCES}

Chierchia, Gennaro (2004) "Scalar Implicatures, Polarity Phenomena, and the Syntax/ Pragmatics Interface," Structures and Beyond: The Cartography of Syntactic Structures, Vol. 3, ed. by Adriana Belletti, 39-65, Oxford University Press, Ox-

${ }^{18}$ I thank Sigrid Beck (personal communication) for bringing the data to my attention. 
ford.

Guerzoni, Elena (2003) Why Even Ask? On the Pragmatics of Questions and the Semantics of Answers, Doctoral dissertation, MIT.

Hamblin, Charles Leonard (1976) "Questions in Montague English," Montague Grammar, ed. by Barbara Partee, 247-259, Academic Press, New York.

Heim, Irene (1983) "On the Projection Problem for Presupposition," WCCFL 2, 114-125.

Heim, Irene and Angelika Kratzer (1998) Semantics in Generative Grammar, Blackwell, Oxford.

Israel, Michael (1999) "Some and the Pragmatics of Indefinite Construal," BLS 25, 169-182.

Kadmon, Nirit (2001) Formal Pragmatics, Blackwell, Oxford.

Karttunen, Lauri and Stanley Peters (1979) "Conventional Implicature," Presupposition, Syntax and Semantics 11, ed. by Kyu Oh and David A. Dinneen, 1-56, Academic Press, New York.

Kobuchi-Philip, Mana (2010) “Indeterminate Numeral Quantifiers, 'Some' and 'Many' Readings, and Questions in Japanese," Korean Journal of Linguistics 35, 503-530.

Kuroda, S.-Y. (1965) Generative Grammatical Studies in the Japanese Language, Doctoral dissertation, MIT.

Lahiri, Uptal (1998) "Focus and Negative Polarity in Hindi," Natural Language Semantics 6, 57-123.

Nakanishi, Kimiko (2008) "Scope of Even: A Cross-Linguistic Perspective," NELS $38,156-166$.

Nakanishi, Kimiko (2010) "Suusi Toritate no Mo to Hitei (Mo that Associates with a Numeral and Negation)," Hitei to Gengo Riron (Negation and Linguistic Theory), ed. by Yasuhiko Kato, Akiko Yoshimura and Ikuni Imani, 260-284, Kaitakusha, Tokyo.

Nishigauchi, Taisuke (1986) Quantification in Syntax, Doctoral dissertation, University of Massachusetts, Amherst.

Nishigauchi, Taisuke (1990) Quantification in the Theory of Grammar, Kluwer, Dordrecht.

Oda, Toshiko (2012) "Numeral Indeterminate Phrases," JELS 29, 128-134.

Ohno, Yutaka (1989) "Mo," Papers on Quantification: University of Massachusetts Occasional Papers Special Edition, 223-250.

Rooth, Mats (1985) Association with Focus, Doctoral dissertation, University of Massachusetts, Amherst.

Ross, John (1984) "Inner Island," BLS 10, 258-265.

Rullmann, Hotze (1995) Maximality in the Semantics of Wh-Constructions, Doctoral dissertation, University of Massachusetts, Amherst.

Rullmann, Hotze (1997) "Even, Polarity, and Scope," Papers in Experimental and Theoretical Linguistics 4, ed. by Martha Gibson, Grace Wiebe and Gary Libben, 40-64, University of Alberta.

Shimoyama, Junko (2006) "Indeterminate Phrase Quantification in Japanese," Natural 
Language Semantics 14, 139-173.

Sudo, Yasutada (to appear) "The Small Reading of the Scalar Particle Mo in Japanese and Negative Polarity," Proceedings of the 7th Logic and Engineering of Natural Language Semantics.

Takahashi, Daiko (1994) Minimality of Movement, Doctoral dissertation, University of Connecticut.

Tancredi, Christopher and Miyuki Yamashina (2002) “Wh-Setsu to 'Mo' no Douteki Sougo Kankei (The Dynamics of Wh-Mo Interaction)," Bunpou Riron: Rekisikon to Tougo (The Theory of Grammar: Lexicon and Syntax), ed. by Takane Ito, 273-299, University of Tokyo Press, Tokyo.

von Stechow, Arnim (1991) "Current Issues in the Theory of Focus," Semantik, ed. by Arnim von Stechow and Dieter Wunderlich, 804-825, Walter de Gruyter, Berlin.

Willkinson, Karina (1996) "The Scope of Even," Natural Language Semantics 4, 193-215.

Yamashina, Miyuki and Christopher Tancredi (2005) "Degenerate Plurals," Sinn und Bedeutung 9, 522-537.

Yatsushiro, Kazuko (2009) "The Distribution of Quantificational Suffixes in Japanese," Natural Language Semantics 17, 141-173.

[received March 28 2012, revised and accepted July 23 2012]

Faculty of Economics

Tokyo Keizai University

1-7-34 Minami-cho, Kokubunji-shi

Tokyo 185-8502

e-mail: toda@tku.ac.jp 